\title{
O (NÃO) USO DE INDICADORES DE GESTÃO EM PROPRIEDADES LEITEIRAS NA GALÍCIA - ESPANHA
}

\author{
C. C. S. CYRNE ${ }^{*}$, C. REMPEL, C. HAETINGER e J. BORTOLI \\ Centro Universitário Univates \\ cyrne@univates.br*
}

Artigo submetido em julho/2015 e aceito em setembro/2015

DOI: 10.15628/holos.2015.3249

\section{RESUMO}

A globalização atinge o setor agroindustrial e afeta a base da produção primária no mundo. De forma natural, a necessidade de profissionalização surge nas propriedades produtoras de leite. Este trabalho teve como objetivo analisar o (não) uso de indicadores de gestão nas propriedades produtoras de leite, a partir dos dados coletados em entrevistas realizadas em 25 propriedades localizadas nas Províncias de Lugo e A Coruña, Galícia, Espanha. Buscou-se uma heterogeneidade na amostra, caracterizada como não probabilística, com a finalidade de compreender o funcionamento das propriedades no controle de suas variáveis, através de indicadores gerenciais. Conclui-se que as propriedades apresentam realidades distintas, sendo observadas propriedades em estágio inicial de acompanhamento de indicadores de gestão e propriedades utilizando ferramentas sistematizadas. A partir dessa constatação, apresenta-se uma oportunidade de intervenção da Universidade na oferta de qualificação para potencializar o resultado das propriedades produtoras de leite.

PALAVRAS-CHAVE: Leite. Galícia. Indicadores. Desempenho.

\section{THE (NON) USE OF MANAGEMENT INDICATORS IN DAIRY FARMS IN GALICIA - SPAIN}

\begin{abstract}
Globalization affects the agribusiness sector and affects the base of primary production in the world. Naturally, the need for professionalization appears in milk producing establishments. This study aimed to analyze the (non) use of management indicators in milk producing establishments, from the data collected in the interviews in 25 properties located in the provinces of Lugo and A Coruña, Galicia, Spain. We tried to heterogeneity in the sample, characterized as non-
\end{abstract}

probabilistic, in order to understand the behavior of properties on the control of its variables, through management indicators. It follows that the properties have different realities, and observed properties at an early stage of monitoring of management and property indicators using systematic tools. From this observation, we present a University of intervention opportunity in qualifying offer to enhance the outcome of farms milk producers.

KEYWORDS: Milk. Galicia. Indicators. Performance. 


\section{INTRODUÇÃO}

O leite constitui-se em um dos principais alimentos em todas as fases da vida dos seres humanos, compõe uma das principais fontes de proteína sendo seu consumo incentivado como fonte de vida saudável, sendo a atividade leiteira, no mundo todo, ligada ao social, pois a produção de leite possibilita a manutenção dos produtores no campo, sendo ora uma fonte de renda adicional, ora a principal fonte, reduzindo o êxodo rural.

Zoccal (2013) afirma que em 2011 a produção mundial de leite foi de 615 bilhões de litros, $37 \%$ na Ásia, 29\% na Europa, 25\% nas Américas, 5\% na África e 4\% na Oceania. Os países que mais se destacam são: Estados Unidos, a Índia, a China, o Brasil e a Rússia.

Importante destacar que, como dito por Duarte (2002), há uma grande variação em nível internacional não só em termos de volume produzido, mas também da produtividade, pois apesar de grandes produtores, como a Índia, a produtividade pode ser baixa, de outro lado Japão e Canadá, por exemplo, possuem baixos volumes e alta produtividade.

A criação de gado bovino na Espanha constitui uma importante atividade econômica, seja para produção de carne ou de leite. As vacas de leite estão em todo o país alcançando em 2014, segundo dados do Ministério da Agricultura e do Meio Ambiente da Espanha, um rebanho de 876.211 animais, com um destaque para a Galícia que concentra $42,66 \%$ dos animais, seguida de Castilla y León e Cantábria, com 10,92\% e 8,70\% respectivamente. Observe-se que a soma da participação das duas Comunidades não alcança $50 \%$ do que representa a Galícia.

De acordo com o Censo Agropecuário Espanhol - 2009, o número de propriedades e de cabeças de gado, de carne e de leite, estão distribuídas nos estratos constantes da tabela 1. Percebe-se a concentração (70\%) nos estratos constituídos por propriedades com até 50 cabeças, porém estas possuem somente $22 \%$ do rebanho total.

Tabela 1: Propriedades de gado por estrato de animais.

\begin{tabular}{l|l|l}
\hline & No propriedades & Cabeças \\
\hline Com menos de $\mathbf{5}$ cabeças & 20.832 & 48.536 \\
\hline De $\mathbf{5}$ cabeças a menos de $\mathbf{1 0}$ cabeças & 13.601 & 92.400 \\
\hline De $\mathbf{1 0}$ cabeças a menos de $\mathbf{2 5}$ cabeças & 23.422 & 378.886 \\
\hline De $\mathbf{2 5}$ cabeças a menos de $\mathbf{5 0}$ cabeças & 20.504 & 729.525 \\
\hline De $\mathbf{5 0}$ cabeças a menos de $\mathbf{1 0 0}$ cabeças & 18.108 & 1.268 .030 \\
\hline Com $\mathbf{1 0 0}$ cabeças ou mais & 15.370 & 3.323 .424 \\
\hline
\end{tabular}

A média é de 52 cabeças sendo também importantes os estratos com menos de cinco animais e os que possuem entre 25 e 50 animais. As propriedades com mais de 100 animais, constituem $13,74 \%$ das propriedades, mas possuem $56,90 \%$ dos animais.

De acordo com os dados do anuário agropecuário espanhol de 2009 o número total de propriedades agropecuárias era de $989.796,23,24 \%$ menor do que em 1999. Nesta mesma direção as propriedades criadoras de bovinos vêm sofrendo uma redução constante sendo de $40 \%$ neste mesmo período, não obstante houve uma diminuição de $8 \%$ no número de cabeças demonstrando uma tendência de concentração, sendo que o número de animais por propriedade cresceu $54,88 \%$ no mesmo período, passando para 55 animais. Mesmo com a 
redução contínua do número de propriedades (47\% entre 2005 e 2013) a produção movimentase na direção contrária tendo crescido 47\% entre 2005 e 2013.

A produção de leite está presente em todo o território espanhol, de uma maneira heterogênea, com um destaque para a Galícia que responde por aproximadamente $40 \%$ de todo leite produzido no país, e tendo $42,66 \%$ das vacas de leite. De acordo com os dados do Ministério de Agricultura, Alimentação e Meio Ambiente a produção de leite na Espanha em 2012 foi de 6.313 .000 de litros, o valor movimentado foi de $€ 2,718$ milhões e foram envolvidas cerca de 900.000 pessoas, sendo $63,5 \%$ de mão de obra familiar.

As Comunidades Autônomas apresentam diferenças nos volumes produzidos, sendo interessante perceber que há uma desaceleração no crescimento e até mesmo a redução da produção em algumas. A exceção é a Andalucía que mantém, em 2011-2012 taxa de crescimento $(13,75 \%)$ idêntica ao período de 2008-2012 (13,99\%), e também o crescimento da produção em Aragón (103,87\%) no período de 2008-2012, mesmo que o volume produzido seja pequeno.

\subsection{Indicadores de desempenho da gestão}

Para a cadeia produtiva do leite a melhoria dos mecanismos de gestão é fundamental, pois a não adoção de técnicas que possibilitem o monitoramento do desempenho da atividade pode implicar na, segundo Souza (2011), exclusão de uma parte significativa dos produtores, visto que o setor entrou na era da competitividade em uma economia globalizada.

Faltam pesquisas sobre o tema, o que, aliado à baixa capacidade para a absorção e a utilização de técnicas e ferramentas gerenciais pelos agricultores, seja pela falta de educação formal, seja pelo ambiente no qual está inserido, reduz o potencial competitivo das propriedades rurais. Essa percepção é confirmada por Canziani (2001), que apresenta considerações sobre a existência de uma associação positiva entre o uso de técnicas de gestão e resultado econômico, porém, isso não é compreendido pelos produtores rurais.

Ainda segundo o autor, houve apoio de instituições de pesquisa agronômica e do setor público para o desenvolvimento e a modernização da produção agrícola e um descuido das questões relativas à capacitação dos produtores, que possuem um "baixo nível de capacidade gerencial” (GALVÃO JÚNIOR; et al., 2015; p.131), para a gestão das propriedades rurais.

A complexidade do agronegócio está exigindo uma mudança no perfil do produtor rural em todo o mundo, é possível dizer, como Canziani (2001) afirma, que são relevantes novas pesquisas que tratem de questões administrativas no meio rural. Porém, administrar a unidade produtora de leite como empresa ainda não faz parte da cultura e da tradição da grande maioria dos produtores.

Bortolini (2010) afirma que, nesse contexto de globalização, é preciso que os produtores rurais tenham a capacidade de ler e interpretar as exigências do ambiente interno e externo à propriedade. É necessário desenvolver capacidades de gerenciamento e isso requer habilidades que, muitas vezes, o agricultor não está acostumado a praticar ou ainda não desenvolveu, fato este confirmado por Eyerkaufer (2007), que declara que faltam habilidades ao produtor, embora busque gerir a propriedade como um negócio.

Em tese, os integrantes da cadeia produtiva precisam desenvolver a capacidade de ler o cenário em que estão inseridos. Alguns produtores, em função de sua posição na cadeia, 
relativamente distante do consumidor final, durante um longo período de tempo preocuparamse mais com os processos internos de suas propriedades e acreditavam que a oferta de seus produtos garantia a demanda, levando ao desmerecimento das questões voltadas às técnicas de gestão.

Viana e Ferras (2007), afirmam que o modelo de gestão das propriedades rurais é motivo de preocupação devido à prevalência da falta de controles, da carência da inserção da tecnologia da informação e do estilo de administração adotado pelos produtores rurais, que tomam suas decisões sem o apoio de sistemas de gestão adequados.

Uma questão central para gerir adequadamente os processos internos ou, ainda, o posicionamento competitivo de uma propriedade rural é a existência de indicadores de desempenho, formalizados ou não. Isso porque a medição de desempenho é fundamental como parte de um processo de planejamento, execução e monitoramento dos processos com o intuito de atingir os objetivos. É importante definir indicadores que possam ser utilizados como parâmetros para medir o desenvolvimento econômico, social e ambiental de propriedades rurais.

A análise dos resultados a partir do uso de indicadores de desempenho serve para dar sustentação às decisões de uma organização. Há necessidade de estabelecer indicadores de curso e longo prazo, permitindo sobreviver e, ao mesmo tempo, construir um futuro desejado.

Diferentes autores tratam da evolução dos sistemas de medição de desempenho entre eles: Bourne, Neely e Platts (2003), Sobreira Netto (2006) e (2007), Souza (2011), Tezza, Bornia e Vey (2010). A partir destes é possível afirmar que o interesse não é recente, porém tem sofrido modificações significativas ao longo do tempo.

De acordo com Bourne et al. (2002) o grande interesse pelos sistemas de medição de desempenho cresceu devido a Harvard Business Review citar o Balanced Scorecard como uma das ferramentas de gestão mais importantes dos últimos 75 anos, isto acabou atraindo o interesse do mundo empresarial e acadêmicos igualmente. Os indicadores como subsídio para a tomada de decisão estão esquematizados na Figura 1.

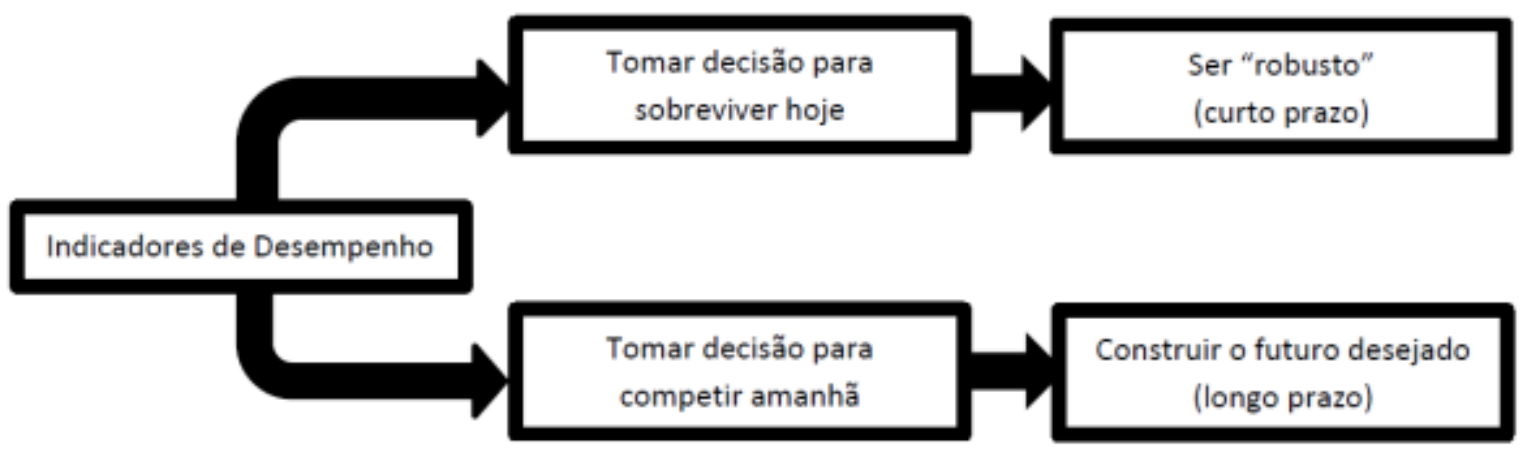

Figura 1 - Indicadores como subsídio para a tomada de decisão Fonte: Elaborado pelos autores

Um indicador de desempenho pode ser descrito como o meio utilizado para medir a eficiência ou a eficácia de uma decisão ou, ainda, como sendo a quantificação de como estão sendo realizadas as atividades, com o propósito de comparar com as metas estabelecidas. Um indicador é um instrumento de medida de desempenho, sendo utilizado para mensurar e analisar os resultados obtidos, de acordo com Nunes (2008). 
A medição de desempenho é fundamental como parte de um processo de planejamento, execução e monitoramento dos processos com o intuito de atingir os objetivos, "na visão organizacional moderna, o desenvolvimento de sistemas de medição de desempenho é fator chave no apoio a gestão, pois possibilita a tomadas de decisões corretas e a tempo, das operações da organização" (SILUK, 2007; p39), segundo Neely, Gregori e Platts (1995) a medição pode ser o processo de quantificação, mas seu efeito é estimular a ação.

Segundo Góis (2009), a medição de desempenho é um campo da ciência da administração, que está na fronteira entre a estratégia gerencial, os sistemas de informação e a teoria das organizações, viabilizando a comparação entre os resultados reais e os ideais. A partir de Callado, Callado e Almeida (2007), é possível afirmar que todas as empresas precisam de um sistema de avaliação de desempenho, pois ele permite verificar o atingimento do resultado esperado de um processo e indica as ações requeridas para a correção de desvios de rota. De acordo com Góis (2009), a mensuração de desempenho revela-se fundamental para a tomada de decisões com base em fatos e dados.

É preciso ter presente que não há um sistema de gestão que possa ser aplicado em todas as situações, como afirmam Neves e Campos (2007). Faz-se necessário buscar as adequações que permitam o melhor resultado em cada caso especificamente. Como afirmam Neely e Adams (2002), não existe um Santo Gral ou uma melhor maneira de visualizar o desempenho dos negócios, pois estes são em si um conceito multifacetado.

Cada empresa precisa definir o seu número de indicadores, não importa quantos são, o importante é como os mesmos serão utilizados, pois, segundo Steffanello e Macedo (2009), não existe um método ou modelo de avaliação de desempenho que seja único. Nessa mesma direção, Nunes (2008) afirma que não existe uma receita para escolher os indicadores, que podem ser financeiros ou não financeiros, internos ou externos. O que realmente importa é que, no conjunto, tenham a capacidade de demonstrar a realidade com a maior transparência possível.

Cabe sublinhar que é importante ter presente que os indicadores não podem ser visualizados de forma isolada e independente, mas como um sistema, que mostre a situação da propriedade, e precisam estar alinhados em toda a cadeia. Rabello (2012) lembra que é comum, no setor de agropecuária, empresários e produtores tomarem decisões a partir de critérios relativos e isolados, da mesma forma que não consideram análise do mercado, demanda pelo produto, custos logísticos, entre outros. O autor considera que são necessárias informação e medição precisas, mas que boa parte das empresas e do setor produtivo negligencia essas informações. Rabello (2012), considera que a falta de um sistema de informações confiáveis faz com que as decisões sejam tomadas com base em um cenário que pode ser equivocado.

\subsection{Produção de leite}

A produção de leite é uma atividade que apresenta a capacidade de manter a população no meio rural, o que potencializa os seus efeitos sobre as economias locais. França (2006), apresenta considerações sobre a importância socioeconômica da atividade leiteira. São elas: a) emprega um expressivo contingente de mão de obra; b) gera excedentes comercializáveis e c) garante renda para os produtores em grande parte dos municípios. Souza (2011) afirma também que a reorganização do setor leiteiro é movida pela exigência de um mercado competitivo. 
Essa condição mostra a exigência de profissionalização da gestão nas propriedades e a medição de seu desempenho por meio de um sistema balanceado de indicadores que seja capaz de situar o agricultor quanto à localização estratégica de sua propriedade, podendo tomar providências o quanto antes em caso de não conformidades em sua produção.

Ao mesmo tempo, quando os padrões são estabelecidos por um ator distante do mercado e que não possui visão adequada da evolução do mercado e do ambiente, corre-se o risco de comprometer-se a competitividade do setor no longo prazo. Para evitar situações desse tipo, seria conveniente que os indicadores de desempenho dos elos da cadeia contemplassem, no mínimo, as perspectivas propostas por Kaplan e Norton (2004), que são: a) aprendizagem; b) operações internas; c) clientes e d) financeiras.

Apesar das divergências, é fundamental que cada unidade produtiva e a cadeia consigam desempenhos, especialmente nos quesitos operacional e financeiro, suficientes para sustentar suas posições competitivas. No entanto, as unidades produtivas não devem alcançar desempenhos muito inferiores às propriedades consideradas de "classe mundial" e o seu sucesso não pode ser refém da implementação de políticas públicas setoriais. Nesses dois casos, as unidades produtivas correriam o risco de comprometer a sua atividade no longo prazo.

De acordo com Viana e Ferras (2007), a cadeia produtiva é formada por um conjunto de atores que estabelecem entre si relações de compra e venda de uma forma articulada e que permite que a cada nova etapa se tenha agregação de valor. De forma geral, pode-se caracterizar a cadeia produtiva do leite como sendo composta por quatro grandes segmentos: a) fornecedores (insumos e máquinas); b) produtores (especializados e não especializados); c) indústria; e d) distribuição para o mercado nacional e internacional.

\section{PROCEDIMENTOS METODOLÓGICOS}

Esta pesquisa caracteriza-se como descritiva, quantitativa, de campo, baseada em dados obtidos por meio da observação in loco, no período compreendido entre outubro e dezembro de 2014, e da análise de registros gerados nas propriedades. Os dados foram coletados em 25 propriedades localizadas nas Províncias de Lugo e A Coruña que possuem as maiores produções de leite da Galícia.

A região da Galícia está situada ao noroeste da Península Ibérica, limitada a oeste e norte pelo Oceano Atlântico, a leste pelas comunidades de Astúrias e de Castela e Leão e ao sul com Portugal. É singular por suas tradições e costumes, tem uma extensão superficial de $29.574,4$ km² $^{2}$ que representa em média 5,8\% da extensão total espanhola. São quatro Províncias: A Coruña, Lugo, Ourense e Pontevedra, com um perímetro é de $1.919 \mathrm{~km}$, em que $610 \mathrm{~km}$ são terrestres e $1.309 \mathrm{~km}$ são costeiros. Seu relevo mescla montanhas e vales fluviais, o verde das pradarias e o azul do mar. É um país agropecuário e possui uma população de aproximadamente 2,8 milhões de habitantes, o que corresponde a $6 \%$ da população espanhola.

Buscou-se uma amostra heterogênea, não probabilística, com a finalidade de compreender o comportamento de diferentes modelos de propriedades rurais em seus tamanhos e capacidades produtivas. O roteiro utilizado para nortear a entrevista era composto por três partes: a) identificação do produtor buscando dados para definir o seu perfil; b) identificação do perfil das propriedades contemplando aspectos tecnológicos e produtivos; e c) 
identificação dos indicadores de gestão utilizados ou não nas propriedades, com a finalidade de identificar o uso de indicadores para auxílio nas decisões.

Para a realização das entrevistas, os produtores foram contatados por telefone, sendo, então, agendada visita às propriedades. Após a coleta, os dados foram analisados por meio de estatística descritiva. Eles são apresentados na forma de frequência relativa, como média (desvio padrão - DP), sendo utilizado o Microsoft Excel para a realização dos cálculos.

\section{RESULTADOS E DISCUSSÃO}

\subsection{O Leite na Galícia}

De acordo com Fernández, Roldós e López (2012), a Galícia tem sua principal atividade econômica no setor agrário com destaque para o setor de gado, que se caracteriza por apresentar propriedades com reduzido tamanho. A importância é tão grande que os Galegos afirmam que "a riqueza pecuária é o grande pulmão da economia galega..., o saco cheio de grãos e a vaca dócil resumem a vitalidade do campo, mas acima de tudo o Tesouro" (OROZA,2006; p.77). Neste contexto Fernández-Lorenzo et al. (2009) afirmam que o leite tem uma importância econômica e social fundamental no meio rural galego.

Cabe destacar o investimento realizado na melhoria genética, a partir de $1887 \mathrm{com}$ a publicação de um Decreto que instalava uma comissão para estudar a crise agropecuária que vivia a Espanha. O Gado galego foi então alvo de atenção e da busca de formas de melhorá-lo. A primeira alternativa foi realizar um cruzamento da rúbia galega com a raça Simmenthal e a flamenga, posteriormente, usou-se também a Schwytz, com um resultado inicial de melhora da conformação morfológica, bem como uma melhoria na capacidade de produção de carne e também de leite de forma mais precoce.

De acordo com González et al. (2012) as propriedades produtoras de gado bovino constituem a base econômica galega, pois são quase $60 \%$ em número e aportam uns $52 \%$ do valor da produção agrária. As propriedades são muito diferentes em termos de especialização e orientação produtiva, tamanho, localização, com suas características familiares e as condições econômicas do seu entorno, neste contexto Fernández-Lorenzo et al. (2009), consideram que a Galícia é a comunidade mais dinâmica, do ponto de vista da produção de leite de toda a Espanha.

Especificamente a cadeia produtiva do leite na Galícia o desenvolvimento da atividade teve um descompasso em relação ao restante da Espanha, tendo seu início em meados da década de 1970, porém as ações realizadas permitiram que o crescimento fosse superior à média espanhola, em 38 anos a produção multiplicou-se por três, saindo de 757 para 2,181 milhões de litros. O peso do estado da Galícia na produção láctea espanhola aumentou de $26 \%$ em 1962, para 36\% em 2000 e em 2013 é de 37\%. Este aumento de produção foi acompanhado do incremento do leite entregue à indústria que passou de 350 milhões de litros em 1970, para mais de 1,960 milhões de litros em 2000, quase cinco vezes mais, chegando a representar $90 \%$ do leite produzido sendo entregue à indústria.

De acordo com Domínguez, Vidal e González (2003) desde 1968, ano em que a Comunidade Econômica Europeia estabeleceu a organização comum dos mercados do setor lácteo, foram implantadas uma série de políticas que tinham como objetivo o equilíbrio entre a 
oferta e a demanda de leite e de produtos derivados, que culminou com a fixação das cotas de produção em 1984/1985, que tem por um lado a finalidade de limitar a produção e por outro controlar os preços.

A partir do ingresso da Espanha na Comunidade Europeia, em 1986, houve modificação na atividade pecuária leiteira Galega. Foi necessário atender a política agrária comum vigente, que continha o estabelecimento das cotas de produção, e também ocorreu a ruptura do protecionismo existente no mercado espanhol, com isto ocorreu uma redução de $83 \%$ nas propriedades.

De acordo com Fernández, Roldós e López (2012), no início deste período, 87\% das propriedades tinham um plantel inferior a 30 vacas, situação que se modificou nos últimos 10 anos, posto que atualmente este tipo de propriedade constitui somente $18 \%$ das propriedades, a maioria das propriedades (35\%) conta com plantéis entre 50 e 99 vacas. No mesmo período a produção de leite cresceu o que permite afirmar que as propriedades que permaneceram tornaram-se mais eficientes.

Os dados do Instituto Galego de Estatística para o ano de 2012 apontam para a distribuição constante na Tabela 2, sendo que das 41407 propriedades 12216 se dedicam a produção de leite.

Tabela 2: Número de propriedades segundo o tamanho (número de vacas) - 2012.

\begin{tabular}{c|c|c|c|c|c}
\hline Estrato & Galicia & A Coruña & Lugo & Ourense & Pontevedra \\
\hline $1-2$ & 9941 & 3327 & 1492 & 435 & 4687 \\
\hline $3-4$ & 4469 & 1955 & 1327 & 304 & 883 \\
\hline $5-9$ & 6124 & 2649 & 2195 & 403 & 877 \\
\hline $10-19$ & 6815 & 2640 & 2949 & 416 & 810 \\
\hline $20-29$ & 4126 & 1442 & 2008 & 214 & 462 \\
\hline $30-49$ & 4705 & 1437 & 2553 & 220 & 495 \\
\hline $50-99$ & 3782 & 1248 & 1991 & 163 & 380 \\
\hline $100-199$ & 1174 & 459 & 517 & 113 & 85 \\
\hline$>=200$ & 271 & 103 & 112 & 39 & 17 \\
\hline
\end{tabular}

Outra maneira de classificar as propriedades, quanto ao seu tamanho, é aferindo-se a área que possuem (em hectares), desta dimensão as propriedades Galegas estão distribuídas conforme pode ser observado na tabela 3. Observe-se que aproximadamente $50 \%$ possuem menos de cinco hectares e que com menos de 10 hectares são quase $70 \%$.

Tabela 3: Propriedades por tamanho em hectares - 2009.

\begin{tabular}{c|c}
\hline Tamanho (em ha) das propriedades da Galícia & № de propriedades \\
\hline$>=0,1 \mathrm{a}<5$ & 37857 \\
\hline$>=5 \mathrm{a}<10$ & 15297 \\
\hline$>=10 \mathrm{a}<20$ & 13503 \\
\hline$>=20 \mathrm{a}<50$ & 10033 \\
\hline$>=50$ & 2281 \\
\hline \multicolumn{2}{r}{ Fonte: Instituto Galego de Estatística }
\end{tabular}

A mudança no cenário requereu ajustes que levaram a dois caminhos: a intensificação da produção, deixando de depender da terra para produzir as forragens e usando um maior volume de alimentos comprados ou concentrando-se territorialmente em algumas poucas bacias leiteiras que concentram a maior parte do rebanho. 
O número de propriedades entre os anos de 2008-2012 reduziu aproximadamente $12 \%$, porém, consultando os dados do Instituto Galego de Estatística - IGE, constata-se que o volume produzido cresceu próximo de 13\%. Garrido, Nistal e Wille-Sonk (2013), atribuem a redução a política de cotas e que se deveria incluir o número de propriedades que cessam temporariamente as atividades produtivas, para que se tivesse um dado mais real do impacto das cotas na concentração em um número cada vez menor de propriedades e com rebanhos maiores.

Segundo os autores foi necessário investir em modernização das máquinas, das instalações, na melhoria genética e incremento do uso de mão-de-obra não familiar. Porém a existência das cotas limita a produção e dificulta o retorno do investimento, pois em sendo ultrapassado os limites de produção há sobretaxação do excedente, ao mesmo tempo com que fizeram com que os investimentos tivessem de ser bem pensados e eficientes.

O ingresso na União Europeia viabilizou acesso aos fundos estruturais europeus, o que possibilitou investimentos nas regiões menos desenvolvidas, porém a disponibilização dos recursos não veio acompanhada de uma capacitação dos produtores para a gestão, de acordo com García (2006), este é um dos problemas estruturais pendentes. Ainda assim houve crescimento na produção (tabela 4) da Galícia, exceto na província de Ourense que produziu em 2011 2/3 do que produzia em 2001.

Tabela 4: Produção de leite de vaca Galícia - 2001-2011.

\begin{tabular}{c|c}
\hline Ano & Leite de vaca (mil de litros) \\
\hline 2001 & 2314419 \\
\hline 2002 & 2314051 \\
\hline 2003 & 2221551 \\
\hline 2004 & 2168990 \\
\hline 2005 & 2258117 \\
\hline 2006 & 2274798 \\
\hline 2007 & 2285786 \\
\hline 2008 & 2308771 \\
\hline 2009 & 2286787 \\
\hline 2010 & 2337545 \\
\hline 2011 & 2472073 \\
\hline onte: Instituto Galego de Estatística, 2014.
\end{tabular}

A especialização da produção fica evidente quando se observa que as propriedades com maior número de animais ( $\geq 200$ ) apresentam um crescimento no volume produção de $68,7 \%$, no período de 2008-2012, seguido das propriedades que contam com um rebanho entre 100 e 199 vacas (36\%), enquanto que os estratos entre 10 e 50 vacas decresceram, em média, 20\% no volume produzido.

Quando a variável econômica é avaliada percebe-se a importância do leite para a Galícia pelo volume de recursos que movimenta anualmente. Se considerarem-se os valores de 2013 para a Espanha e aplicar um percentual idêntico a produção ter-se-ia aproximadamente $€ \$$ 1.005.000,00. Já na dimensão social, com base nos dados do IGE, a mão de obra utilizada é de aproximadamente 90.000 pessoas e predominantemente familiar (90\%).

A partir deste cenário surge um novo perfil para o setor, o que é confirmado por Souza (2011), quando afirma que a reorganização do setor leiteiro é movida pela exigência de um mercado competitivo. Essa reorganização setorial exigiu e exige que os diferentes elos da cadeia 
leiteira atuem de forma cooperativa e alinhada para que possam garantir a competitividade. Posto isso, é preciso que a cadeia conheça a si mesma, seus elos, suas relações e o valor agregado em cada um dos elos que a constitui.

Tabela 5: Volume produzido (1.000 L) por número de animais por propriedade, conforme estrato de número de animais de 2008 a 2012.

\begin{tabular}{c|c|c|c|c|c}
\hline Estrato & 2008 & 2009 & 2010 & 2011 & 2012 \\
\hline $1-2$ & 271 & 267 & 267 & 301 & 324 \\
\hline $3-4$ & 393 & 332 & 351 & 424 & 433 \\
\hline $5-9$ & 1091 & 982 & 1025 & 1035 & 1050 \\
\hline $10-19$ & 2580 & 2402 & 2188 & 2110 & 2070 \\
\hline $20-29$ & 2339 & 2198 & 2119 & 2032 & 1868 \\
\hline $30-49$ & 3344 & 3228 & 3037 & 2810 & 2675 \\
\hline $50-99$ & 2746 & 2790 & 2825 & 2787 & 2695 \\
\hline $100-199$ & 667 & 727 & 792 & 845 & 907 \\
\hline$>=200$ & 115 & 124 & 155 & 174 & 194 \\
\hline & & \multicolumn{4}{|l}{}
\end{tabular}

Fonte: Instituto Galego de Estatística, 2014.

De acordo com Dias e Oliveira (2005), a cadeia produtiva do leite continua apresentando algumas dificuldades, tais como: a) a desorganização entre os diferentes elos; b) a instabilidade dos preços pagos ao produtor; c) o oligopólio do mercado varejista; e d) a concorrência do leite importado.

Este estudo foca em um dos elos da cadeia, centrando sua atenção em propriedades produtoras de leite na região da Galícia, Espanha, tendo em vista a expressiva contribuição econômica e social que representam, bem como teve por objetivo identificar os indicadores de gestão que estão sendo utilizados, ou não, pelos produtores de leite na gestão de suas propriedades.

As propriedades possuem, em média 32 (DP 17) hectares de extensão, pode-se afirmar a partir do cálculo do desvio padrão (17 hectares) que não há uma homogeneidade no tamanho das propriedades, mas todas podem ser consideradas pequenas, sendo adquiridas com recursos próprios e como resultado de herança em $96 \%$ dos casos. O leite é a principal atividade sendo constatada também a criação de suínos e a agricultura, prevalentemente para produzir insumos para a alimentação dos animais, em $12 \%$ e $8 \%$ das propriedades, respectivamente. No que tange à geração de renda, em $80 \%$ das propriedades, $100 \%$ da renda é oriunda do leite, em $20 \%$ a complementação da renda provém das aposentadorias ou da atuação como engenheiro agrícola, empregada doméstica, vendedor de sêmen e do aluguel de imóveis.

As propriedades possuem em média 95 (DP 54) animais; já o número médio de vacas em lactação é de 52 (DP 30) animais. No que diz respeito ao volume produzido, também se constata uma variação relevante, obtendo-se, como média 42.600 (DP 27.865) litros/mês, com uma amplitude significativa, havendo produtores com produção de 6.000 litros/mês até 100.000 litros/mês. Esta situação pode ser considerada como um ponto a ser destacado, pois o mercado espanhol demanda leite para além da oferta, porém a produção é limitada pelo sistema de cotas estabelecido pela União Europeia. Acredita-se que com o fim desta restrição, ocorrida em abril de 2015 , a produção tenda a aumentar.

Em $88 \%$ das propriedades há presença de computadores e em $76 \%$ delas há acesso à internet. Das 25 propriedades analisadas 15 (60\%) contam com funcionários, sendo na moda um 
funcionário por propriedade. A mão de obra é predominantemente familiar (100\%), pois mesmo as que possuem empregados envolvem familiares na atividade, sendo a moda um e a média de 1,64 familiar por propriedade. A raça presente nas propriedades é predominantemente a Holandesa (100\%). Em 100,0\% das propriedades é usada a técnica de inseminação artificial.

A ordenha é mecanizada em $92,0 \%$ e robotizada em $8 \%$ das propriedades, $100,0 \%$ delas possuem resfriador com capacidade média de 3800 litros, sendo encontrados resfriadores de 800 até 10.000 litros. A presença de resfriadores é uma condição indispensável para a manutenção da qualidade do leite produzido até o momento que seja enviado à indústria, pois sem o resfriamento o produto tende a estragar. Observe-se a amplitude em termos de capacidade dos resfriadores, esta está diretamente relacionada com o volume de produção, também muito amplo.

A alimentação dos animais se dá basicamente com silagem, feno, suplemento concentrado e pasto. O sistema de produção é predominantemente confinado (72\%), ou, ainda, semiconfinado (28\%), não sendo constatado a produção exclusivamente a pasto.

Em relação a máquinas e equipamentos, os mais frequentes são o trator, a ensiladeira, o carretão, a ordenhadeira e o resfriador. As propriedades contam com silos para armazenamento de insumos, estábulos, galpão para as máquinas e esterqueiras e boxes para os bezerros. Um ponto observado durante as visitas in loco é que as construções são em alvenaria e encontram-se em muito bom estado de conservação.

Para a manutenção e ampliação das atividades na propriedade $88 \%$ dos produtores se valem de recursos próprios e financiamentos. Em $76 \%$ das propriedades se faz a separação entre os gastos da propriedade e da família, sendo este um indicativo da profissionalização na gestão do negócio. Os produtores afirmam que resultados auferidos são aplicados em investimentos no leite $(96 \%)$ e nas despesas familiares (100\%). Reinvestir é condição para a manutenção do negócio.

Já os produtores possuem idade média de 47 (DP 8) anos, são casados (80\%) e possuem em média 2 (DP 0,5) filhos. Os produtores estão na atividade rural em média ha 21 (DP 12) anos, sendo observada grande variação, tendo sido encontrados produtores atuando há 40 anos e produtores com tão somente dois anos de atuação na produção de leite. .

A escolaridade predominante é o fundamental completo (56\%), seguido do ensino médio completo e superior completo com $16 \%$ cada. Importante destacar que a qualificação dos produtores tende a melhorar os processos de gestão.

Os entrevistados são associados a sindicatos (60\%) e buscam aperfeiçoamento (92\%) de maneira eventual (80\%), principalmente no contato com o pessoal técnico $(100 \%)$ das cooperativas com quem negociam sua produção, por meio de jornais e revistas (48\%), internet (44\%) e publicações técnicas (40\%). A busca de aperfeiçoamento, mesmo que eventual, é algo a ser destacado, pois há convicção de que os desafios nos processos de produção e gestão só poderão ser superados por pessoas, e empresas, capacitadas para tal.

Quanto aos indicadores, os registros são realizados de forma manual em $56 \%$ das propriedades, mesmo que existam computadores (88\%) e acesso à internet (76\%). Já $12 \%$ dos produtores não realizam registros. Neste ponto importante destacar a dificuldade encontrada para coletar os dados, mesmo que os produtores tenham presente da importância de fazê-lo 
afirmam que não possuem tempo para dedicar-se a esta tarefa, pois as demais atividades Ihes ocupam o dia todo.

Em 92\% das propriedades mede-se a produtividade por animal. O índice de fecundidade é acompanhado por $84 \%$ dos produtores. O volume de leite consumido pelos bezerros e pela família é controlado em $56 \%$ e $8 \%$ das propriedades, respectivamente. A taxa de descarte das vacas é controlada em $72 \%$ das propriedades.

No campo das finanças, $68 \%$ dos produtores calculam a margem líquida do negócio e somente $35 \%$ afirmam calcular a rentabilidade do negócio. O acompanhamento, de forma separada, das receitas da comercialização do leite ou de outros produtos é realizado em somente $16 \%$ das propriedades. O percentual pode ser explicado pelo pequeno número (5) de propriedades que exploram outra atividade além do leite. O fluxo de caixa é acompanhado por $44 \%$ dos produtores, mesmo percentual que calcula o ponto de equilíbrio do negócio. Desempenho menor foi constatado quando o indicador é o cálculo do custo de oportunidade, em que $64 \%$ dos produtores não realizam essa avaliação.

No grande grupo "finanças" tem-se presente um quadro interessante, pois embora alguns indicadores sejam avaliados ainda há necessidade de qualificar o uso dos dados, transformando em informação para subsidiar decisões.

Os estoques de insumo são acompanhados em $68 \%$ das propriedades. De outro lado, o acompanhamento dos custos com mão de obra não é realizado em $56 \%$ das propriedades. Acredita-se que a pouca importância atribuída a esse item é consequência da utilização prevalente de mão de obra familiar, sendo pequeno o número de funcionários e não sendo estabelecida uma dinâmica de remuneração dos integrantes do grupo familiar.

Quanto o item analisado são os gastos, verifica-se os seguintes percentuais de propriedades realizando controles: com medicamentos para os animais (84\%), gastos com manutenção de equipamentos (80\%), gastos com a manutenção das instalações (72\%), gastos com energia (96\%) e os gastos com veterinários (96\%) estão na pauta das propriedades; assim como os investimentos: em equipamentos (72\%) já na aquisição de animais o percentual é menor (44\%), tendo em vista a recria ser utilizada como forma predominante de incremento do rebanho. Acredita-se que a atenção dispensada a este grupo de indicadores deva-se aos volumes de recursos que envolvem, bem como a sua eventualidade, requerendo por vezes a tomada de financiamento para a sua realização.

Em termos ambientais, as preocupações concentram-se em gerenciar a destinação dos dejetos e gerenciar o uso de agrotóxicos e fertilizantes (96\%), e monitorar o uso da terra (88\%). Neste conjunto de indicadores constata-se uma possibilidade de avanço, pois questões ambientais têm crescido de importância.

As empresas tomando consciência desta nova situação devem movimentar-se para atender às exigências legais, a fiscalização, atentando para os custos envolvidos, devem buscar acesso à tecnologia, acesso à informação, bem como estar atentas aos requisitos apresentados pelo mercado consumidor que passou a exigir produtos "ambientalmente corretos". É preciso encontrar uma nova forma de produzir e consumir, pois só assim poder-se-á mitigar os efeitos nocivos sobre o meio ambiente. Para tanto, o engajamento das empresas na busca de uma gestão ambiental eficaz é fundamental. 


\section{CONCLUSÃO}

A partir da coleta de dados é possível afirmar que existem duas realidades antagônicas: de um lado, propriedades em estágio inicial de acompanhamento de indicadores de gestão e, de outro, propriedades utilizando ferramentas sistematizadas em que os principais indicadores utilizados dizem respeito ao controle dos custos envolvidos na produção. Será necessário o esforço conjunto dos diferentes atores para qualificar a gestão das propriedades produtoras de leite, sendo esse um papel que pode ser desenvolvido pela universidade.

\section{REFERÊNCIAS}

1. BORTOLINI, G. Gestão da Pequena Unidade Familiar Produtora de Leite: um modelo de gestão através da compreensão da unidade de produção. 2010. 57 f. Monografia (Especialização em Gestão do Agronegócio) - Especialização em Gestão do Agronegócio, Unisinos, São Leopoldo.

2. BOURNE, M., NEELY, A., MILLS, J., PLATTS, Ken. The success and failure of performance measurement initiatives - perceptions of participating managers. International Journal of Operations \& Production Management, v.22, n.11, p. 1288-1310, 2002.

3. BOURNE, M., NEELY, A., MILLS, J., PLATTS, Ken. Implementing perfance measurement systems: a literature review. International Journal Business Performance Management, v.5, n.1, 2003.

4. CALLADO, A. L. C., CALLADO, A. A. C., ALMEIDA, M. A. A Utilização de Indicadores Gerenciais de Desempenho Industrial no Âmbito de Agroindústrias. Revista Eletrônica Sistemas \& Gestão, v. 2, n. 2, p. 102-118, 2007. Disponível em: <http://www.uff.br/sg/index.php/sg>. Acesso em: 01 jul. 2013.

5. CANZIANI, J. R. F. Assessoria Administrativa a Produtores Rurais no Brasil. 2001, 237 f. Tese (Doutorado em Ciências - Área de Concentração: Economia Aplicada), Escola superior de Agricultura Luiz de Queiroz, Piracicaba.

6. DIAS, T., OLIVEIRA, T. Assessoramento e indicadores técnicos e econômicos de propriedades leiteiras conveniadas ao projeto Educampo - Sebrae em Itutuituba - MG. VIII Simpósio, FGV, 2005.

7. DOMínGUEZ, J. C. M., VIDAL, T. P., GONZÁLEZ, X. A. R. Tendencias Productivas em las Explotaciones deLeche Gallegas. Revista Galega de Economía, v.12, n.1, p.1-18, 2003.

8. DUARTE, V. N. Caracterização dos principais segmentos da cadeia produtiva do leite em Santa Catarina. 2002. 135 f. Dissertação (Programa de Pós-graduação em Engenharia de Produção) - UFSC, Florianópolis.

9. EYERKAUFER, M. L. Contabilidade Gerencial na Gestão de Propriedades Rurais: um estudo das propriedades leiteiras no extremo oeste do Estado de Santa Catarina. 2007. $151 \mathrm{f}$. Dissertação (Mestrado em Ciências Contábeis) - Programa de Pós-Graduação de Ciências Contábeis, Universidade Regional de Blumenau, Blumenau.

10. FERNÁNDEZ, S. I., ROLDÓS, C. E., LÓPEZ, C. J. A. Metología para Medir La Eficiencia en Las Explotaciones de Vacuno Lechero de Galicia. In: XVI CONGRESSO INTERNACIONAL DE INGENIERÍA DE PROYECTOS. Valencia. Resumos, 11-13 de julho de 2012. 
11. FERNÁNDEZ, L. B., DAGNAC T., GONZÁLEZ, A. A., VALLADARES J., PEREIRACRESPO S., FLORES, G. Sistema de Producción de Leche en Galicia. Evolución y estado actual. Revista de la Sociedad Española para el Estudio de los Pastos. Espanha, v.9, n.32, p.251-294, 2009.

12. FRANÇA, S. R. A. Perfil dos Produtores, Características das Propriedades e Qualidade do Leite Bovino nos Municípios de Esmeralda e Sete Lagoas - MG. 2006. 112 f. Tese (Doutorado em Ciência Animal) - Escola de Veterinária - Produção Animal, Universidade Federal de Minas Gerais, Belo Horizonte.

13. GALVÃO JÚNIOR, J.G.B., RANGEL, A.H.N., GUILHERMINO, M.M., NOVAES, L.P., MEDEIROS, H.R. Perfil dos Sistemas de Produção de Leite Bovino no Seridó Potiguar. HOLOS, Ano 31, Vol.2, 2015.

14. GARCÍA, F. S., IGLESIAS, E. L. O Crescimento da Gandaría Galega no período 1960-2000. In: MARTínEZ, Carlos García; OROZA, Herminia Pernas; CERVIÑO, Maria Xosé Fernández. A Gandaría, tesouro da Galícia. A Coruña: Museo do Pobo Galego, 2006.

15. GARRIDO, C. L., NISTAL, F. B., WILLE-SONK, S. Evolución das Explotacións Galegas de Leite Entre 2008 e 2011. Revista Afriga, ano XIX, n.5, 2013. Disponível em: <http://revistaafriga.com/noticias/hemeroteca-revista-afriga/> Acesso em: 12 nov. 2014.

16. GÓIS, M. J. S. Mensuração de Desempenho nas Organizações: a gestão de indicadores na Biblioteca de Ciências Humanas da UFC. 2009. 135 f. Dissertação (Mestrado em Políticas Públicas e Gestão) - Curso de Mestrado em Políticas Públicas e Gestão. Universidade Federal do Ceará, Fortaleza.

17. GONZÁLEZ, I. V., PÉREZ, M. F. M., GARCÍA, F. S., FERNÁNDEZ, R. L., ARIAS, A. I. G., FRA, M. P. Caracterización productiva y relaciones com el territorio de las explotaciones de bovino em Galicia. Madrid: Ministerio de Agricultura, Alimentación y Medio Ambiente, Revista Española de Estudios Agrosociales y Pesqueros, n.233, p.69-100, 2012.

18. INSTITUTO GALEGO DE ESTATÍ́STICA. Disponível em: <www.ige.eu>. Acesso em: 05 nov. 2014.

19. INSTITUTO NACIONAL DE ESTADÍSTICA. Disponível em: <www.ine.es>. Acesso em: 05 nov. 2014.

20. KAPLAN, R., NORTON, D. Mapas estratégicos. Rio de Janeiro, Elsevier, 2004.

21. MINISTÉRIO dE AGRICULTURA, ALIMENTACIÓN Y MEDIO AMBIENTE. Disponível em: <www.magrama.gob.es/es>. Acesso em: 05 nov. 2014.

22. NEELY, A., GREGORY, M., PLATTS, K. Performance measurement system design. International Journal of Operations \& Production Management, v. 15, Iss 4, p.80-116, 1995.

23. NEELY, A., ADAMS, C. The Performance Prism. Centre for Business Performance, 2002. Disponível em: http://www.som.cranfield.ac.uk/som/cbp/index.htm. Acesso em: 31 out. 14.

24. NEVES, M. F., CAMPOS, E. M. Planejamento e gestão estratégica para o leite em São Paulo. 1. ed. São Paulo: SEBRAE, 2007.

25. NUNES, A. V. S. Indicadores de Desempenho para as Micro e Pequenas Empresas: uma pesquisa com as MPE's associadas a Microempa de Caxias do Sul. 2008,107 f. Dissertação (Mestrado em Administração) - Programa de Pós-Graduação do Mestrado em Administração, Universidade de Caxias do Sul, Caxias do Sul. 
26. OROZA, H. P. O Xermolo do Progresso: a orientación pecuária da agricultura Galega (século XIX e primeiro terzo do XX). In: MARTínEZ, Carlos García; OROZA, Herminia Pernas; CERVIÑO, Maria Xosé Fernández. A Gandaría, tesouro da Galícia. A Coruña: Museo do Pobo Galego, 2006.

27. RABELLO, L. Planejamento e Gestão na Produção Pecuária. In: BARBOSA, Fabiano Alvim et al. V Simpósio Nacional Sobre a Produção e Gerenciamento da Pecuária de Corte. Belo Horizonte: UFMG, 2012.

28. SILUK, J. C. M. Modelo de gestão organizacional com base em um sistema de avaliação de desempenho. 2007, 176 f. (Doutorado em Engenharia de Produção) Programa de Pósgraduação em Engenharia de Produção. Universidade Federal de Santa Catarina.

29. SOBREIRA NETTO, F. Medição de desempenho do gerenciamento de processos de negócio BPM no PNAFE: uma proposta de modelo. São Paulo: USP, 2006.

30. SOBREIRA NETTO, F. Medição de desempenho organizacional: um estudo das vantagens e desvantagens dos principais sistemas sob as óticas teórico-acadêmica e de práticas de mercado. In: XXXI Encontro da Anpad, Rio de Janeiro, 2007.

31. SOUZA, R. M. H. A Influência do Ambiente Institucional e Organizacional no Desenvolvimento Rural de Propriedades Produtoras de Leite na Região Extremo-Oeste Catarinense. 2011. 125 p. Dissertação (Mestrado em Desenvolvimento Regional e Agronegócios) - Programa de Mestrado em Desenvolvimento Regional e Agronegócios, Universidade Estadual do Oeste do Paraná, Toledo, 2011.

32. TEZZA, R., BORNIA, A. C., VEY, I. H. Sistemas de medição de desempenho: uma revisão e classificação da literatura. Gestão da produção, São Carlos, v.17, n.1, p.75-93, 2010.

33. VIANA, G., FERRAS, P. R. A Cadeia Produtiva do Leite: um estudo sobre a organização da cadeia e sua importância para o desenvolvimento regional. Revista Capital Científico, Guarapuava, v.5, n.1, jan./dez. 2007.

34. ZOCCAL, R. Produção Mundial e Nacional de Leite. In: FERNANDES, Elizabeth Nogueira et al. Alternativas para produção sustentável da Amazônia. Brasília, DF: Embrapa, 2013. 